\section{Aortoesophageal fistula following Polyflex stent placement for refractory benign esophageal stricture}
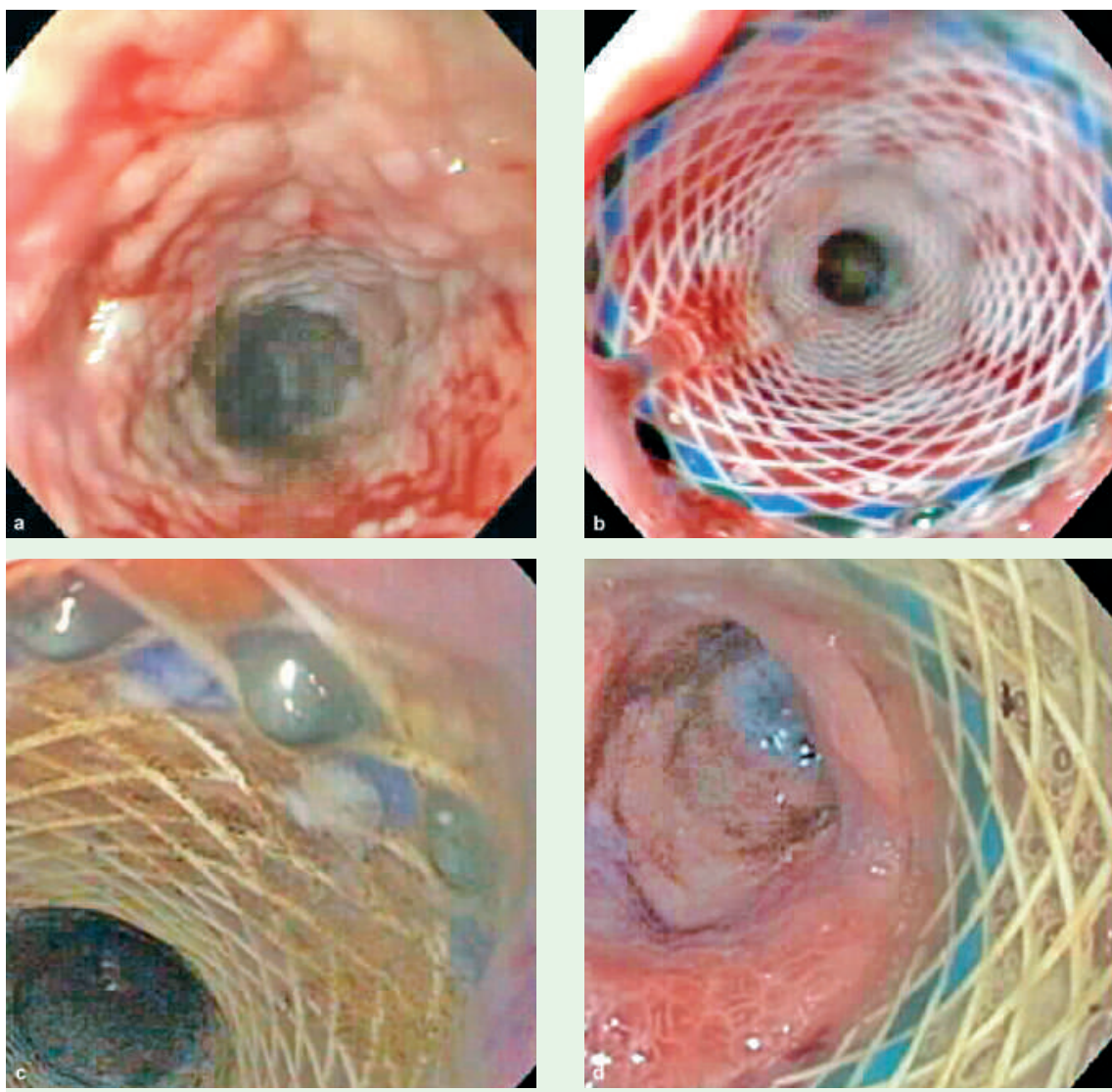

Fig. 1 Polyflex stent placement. After the first stent was removed, endoscopy revealed a patent esophageal lumen and mucosal indentation (a). Six weeks after recurrence of the dysphagia, a second Polyflex stent was placed (b). Endoscopy 6 months and 8 months later revealed no evidence of tissue hyperplasia at the proximal (c) or distal (d) stent margins.

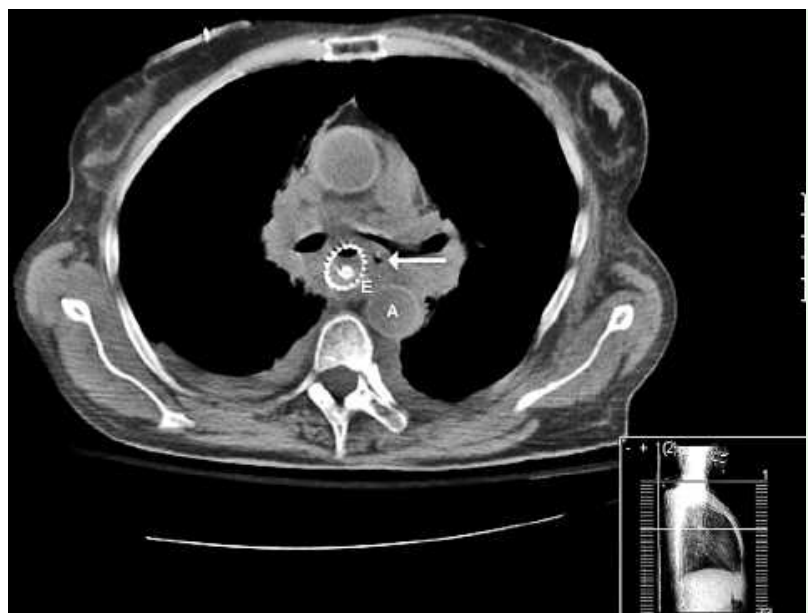

Fig. 3 A noncontrast computed tomographic scan of the chest 51 weeks after Polyflex placement, when the patient presented with massive hematemesis. The stent and a nasogastric tube can be seen, with a thickened esophageal wall and loss of the fat plane between the aorta (A) and the esophagus (E). A small area of mediastinal air (arrow) is seen posterior to the left main-stem bronchus, suggesting esophageal perforation.

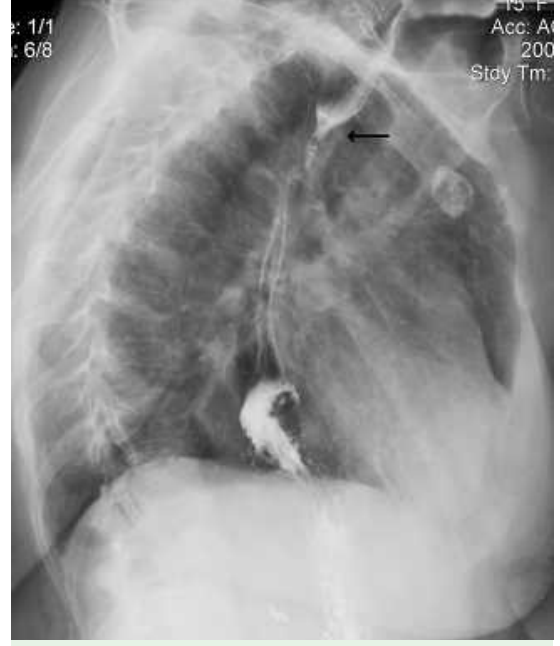

Fig. 2 Barium esophagram after the first Polyflex stent was removed. There is a stricture of the proximal esophagus in close proximity to the aortic arch (arrow) and proximal dilatation of the cervical esophagus. Marked spinal kyphosis is seen in this lateral view.

A 68-year-old woman with a history of Barrett's esophagus, spinal kyphosis, and Hodgkin's lymphoma, who had been treated with mediastinal radiation 25 years before, presented with a radiationinduced, refractory benign esophageal stricture that had shown only a limited response to monthly balloon dilations. Endoscopy identified an esophageal stricture extending from $21 \mathrm{~cm}$ to $23 \mathrm{~cm}$. After controlled radial expansion balloon dilation, a $16 \mathrm{~mm} \times 9 \mathrm{~cm}$, removable, self-expanding plastic stent (Polyflex; Boston Scientific, Natick, Massachusetts, USA) was deployed across the stricture. Her dysphagia resolved and the stent was removed 2 months later ( $\bullet$ Fig. 1).

Two weeks later she presented with symptomatic stricture recurrence (- Fig. 2). An $18 \mathrm{~mm} \times 9 \mathrm{~cm}$ Polyflex stent was placed, again with resolution of the dysphagia, and endoscopy at 6 months and at 8 months revealed the stent to be well positioned, without any evidence of tissue hyperplasia ( $\bullet$ Fig. 1). At 11 months, she presented with hematemesis and hypotension. Endoscopy identified massive bleeding at the proximal stent margin, and computed tomography revealed signs suggestive of esophageal perforation ( Fig. 3). The patient died after an emergency thoracotomy, which had revealed erosion of the stent through the esophageal wall into the posterior surface of the aortic arch, with surrounding inflammation and adhesions. 
Aortoesophageal fistula is a rare, usually fatal, cause of upper gastrointestinal bleeding, and has not previously been reported following placement of self-expanding plastic stents. Our patient had recurrence of a post-radiation refractory benign esophageal stricture after Polyflex stent removal and a program of prolonged placement was then pursued. Factors which might have increased the risk of serious complications in this case include: female gender, prior radiation therapy [1], proximal stricture location [2], kyphosis [3], and intestinal metaplasia [4]. While removable self-expanding plastic stents are a promising tool in the treatment of refractory benign esophageal stricture [5], caution is warranted with prolonged placement. Further data regarding their long-term safety, comparison with other management strategies, and identification of risk factors for serious complications are required.

\section{Competing interests: None}

Endoscopy_UCTN_Code_CPL_1AH_2AD

\section{J. Rogart ${ }^{1}$, A. Greenwald ${ }^{2}$, F. Rossi ${ }^{1}$, P. Barrett ${ }^{3}$, H. Aslanian'}

1 Department of Medicine, Section of Digestive Diseases, Yale University School of Medicine, New Haven, Connecticut, USA

2 Digestive Disease Associates, New London, Connecticut, USA

3 Department of Surgery, Yale University School of Medicine, New Haven, Connecticut, USA

\section{References}

1 Kinsman KJ, DeGregorio BT, Katon RM et al. Prior radiation and chemotherapy increase the risk of life-threatening complications after insertion of metallic stents for esophagogastric malignancy. Gastrointest Endosc 1996; 43: 196-203

2 Kawasaki R, Sano A, Matsumoto S. Longterm outcomes and complications of metallic stents for malignant esophageal stenoses. Kobe J Med Sci 2003; 49: 133-142

3 Demarquay JF, Conio M, Dumas R et al. Fatal complication after placement of an esophageal self-expanding metal stent. Am J Gastroenterol 1996; 91: $178-179$
4 Guillem P, Porte H, Techer E, Wurtz A. Aortoesophageal fistula of uncommon origin: perforation of a Barrett's ulcer. Dis Esophagus 2003; 16: 259-260

5 Evrard S, Le Moine O, Lazaraki G et al. Selfexpanding plastic stents for benign esophageal lesions. Gastrointest Endosc 2004; 60: 894-900

Bibliography

DOI 10.1055/s-2007-966803

Endoscopy 2007; 39: E321-E322

(c) Georg Thieme Verlag KG Stuttgart · New York . ISSN 0013-726X

Corresponding author

\section{J. N. Rogart, MD}

Department of Internal Medicine, Section of Digestive Diseases Yale University School of Medicine 333 Cedar Street - 1080 LMP

PO Box 208019

New Haven

Connecticut 06520-8019

USA

Fax: +1-203-737-1755

jason.rogart@yale.edu 